\title{
Juventude e ações sócio educativas no Brasil
}

\author{
Juarez Dayrell \\ Geraldo Leão*
}

\begin{abstract}
Resumen
El artículo pretende reflexionar sobre la naturaleza socioeducativa de las acciones públicas dirigidas a los jóvenes pobres en la periferia de la Región Metropolitana de Bello Horizonate, discutiendo sus significados desde el punto de vista de los jóvenes y el carácter de protagonismo juvenil propuesto por la gran mayoría de estos proyectos. Se constata la existencia de una "pedagogía de la precariedad" y se apunta a los límites y a las posibilidades de la dimensión socioeducativa presente en esas acciones.
\end{abstract}

Palabras clave: Juventud, Educación, Políticas Públicas

\section{Resumo}

O artigo pretende refletir sobre a natureza sócio educativa das ações públicas dirigidas a jovens pobres na periferia da Região Metropolitana de Belo Horizonte, discutindo os seus significados no ponto de vista dos jovens e o caráter do protagonismo juvenil proposto pela grande maioria desses projetos. Constata-se a existência de uma "pedagogia da precariedade" e apontam-se os limites e as possibilidades da dimensão sócio educativa presentes nessas ações.

Palavras chave: Juventude, Educação, Políticas Públicas

\footnotetext{
Juarez Dayrell é brasileiro, professor da Faculdade de Educação da Universidade Federal de Minas Gerais e coordenador do Observatório da Juventude da UFMG. Email: juareztd uol.com.br

Geraldo Leão é brasileiro, professor da Faculdade de Educação da Universidade Federal de Minas Gerais e subcoordenador do Observatório da Juventude da UFMG. Email: gleao2001 yahoo.com.br

Além dos autores citados, o texto contou com a colaboração de parte da equipe do Observatório da Juventude da UFMG, composta pelo professor Cláudio Santos, Juliana Batista Reis e as bolsistas Tatiane Alves Costa e Fernanda Almeida de Carvalho com o apoio de Anna Beatriz F. Andrade. Agradecemos o apoio da Pró Reitoria de Pesquisa da UFMG; FAPEMIG e CNPQ.
} 


\section{Introdução}

Este trabalho pretende refletir sobre a natureza sócio educativa das ações públicas dirigidas a jovens pobres na periferia da Região Metropolitana de Belo Horizonte, discutindo os seus significados no ponto de vista dos jovens e o caráter do protagonismo juvenil proposto pela grande maioria desses projetos.

A partir do final da década de 1990, assistimos no Brasil uma ampliação significativa das políticas públicas de juventude nos níveis federal, estadual e municipal, mesmo que ainda apresente uma abrangência limitada em relação ao conjunto do universo juvenil. Ao mesmo tempo, vem crescendo também a presença de Organizações Não Governamentais (ONGs) que, com financiamento próprio ou em parcerias com o poder público, vêm ampliando sua presença nas periferias dos grandes centros urbanos. Tais ações, resguardando as suas especificidades, caracterizamse, geralmente, por desenvolverem ações educativas para jovens, voltadas ora para a formação da cidadania, ora para profissionalização. Essas ações visam também a uma formação geral, muitas vezes através de conteúdos artísticos culturais, apostando em uma metodologia que enfatiza o protagonismo juvenil. Assim sendo, há uma tendência dominante nos diferentes programas e projetos em priorizar o desenvolvimento de ações de natureza sócio educativa. Aparece quase como óbvio: é necessário "educar" os jovens pobres.

Como nos lembrava Darci Ribeiro (1989), é necessário questionar o óbvio para que possamos desnaturalizá-lo. É esta a nossa pretensão: por que as atividades dirigidas a jovens pobres tendem sempre a enfatizar a dimensão sócio educativa? Qual é a lógica que as informa? Quais os seus impactos na vida dos jovens? Quais os possíveis significados da proposta de "protagonismo juvenil" presente na maioria delas? Quais os efeitos desta tendência sobre as representações que a sociedade elabora acerca da relação entre juventude e pobreza? 
Para desenvolver a reflexão proposta, tomaremos como referência empírica os dados da pesquisa Políticas Públicas para a Juventude na Região Metropolitana de Belo Horizonte, parte local da investigação nacional Juventude, Escolarização e Poder Local, realizada entre 2003 e 2005 na Região Metropolitana de Belo Horizonte $(\mathrm{RMBH})^{1}$. Inicialmente faremos uma reflexão sobre as formulações do Programa em Belo Horizonte, seguida por uma descrição analítica do seu funcionamento e seus impactos no ponto de vista dos jovens. Em seguida, buscaremos problematizar os possíveis significados e limites da sua dimensão sócio educativa.

\section{O Programa Agente Jovem}

\section{O Programa Agente Jovem de Desenvolvimento Social e Humano foi criado em 2000 pela Secretaria de Assistência Social do Ministério da Previdência Social. Neste mesmo ano, foi implantado em Belo Horizonte através da Secretaria Municipal de Assistência Social, ampliando-se gradativamente até atingir 40 núcleos em toda ci- dade ${ }^{2}$. Cada núcleo contempla 25 jovens na faixa etária compre- endida entre 15 e 17 anos, atingindo um total de 1000 jovens.}

O programa visa proporcionar uma oportunidade de "ocupação para jovens de 15 a 17 anos em situação de risco e vulnera-

1 Juventude, Escolarização e Poder Local é uma pesquisa nacional, coordenada pelos professores Marília Spósito (USP) e Sérgio Haddad (PUC-SP), cujos eixos centrais foram mapear e analisar as ações municipais destinadas à juventude e a Educação de Jovens e Adultos em 75 cidades do Brasil. Tal pesquisa teve como objetivos gerais conhecer e descrever as ações públicas destinadas aos jovens implementadas por esses municípios, analisando o modo como são estabelecidas as relações com os próprios segmentos juvenis destinatários das políticas implantadas pelo governo municipal, além de uma análise dos modos como vêm sendo construídas as políticas públicas destinadas aos jovens na região. Em Belo Horizonte a primeira fase foi de caráter quantitativo, abrangendo 12 municípios da RMBH. Na segunda fase, de caráter qualitativo, foi desenvolvido um estudo de caso em torno do Programa Agente Jovem, sendo pesquisados três núcleos do Programa. O relatório completo da pesquisa encontra-se em Dayrell (2005).

2 Em 2000 foi implementado um plano piloto com seis núcleos em diferentes regiões de BH, dentre eles o Alto Pereira, um dos núcleos investigados. Em 2001, estabeleceramse convênios com entidades da sociedade civil, segundo a Lei de Parcerias de Belo Horizonte, sendo ampliado para 20 núcleos. Em 2002, foram implantados outros 14 núcleos intermediados pelo programa "BH Cidadania", quando passou a funcionar o outro núcleo pesquisado, o 7 de Setembro, resultando num total de 40 núcleos, número existente até hoje. 
bilidade social", criar condições para a inserção, a reinserção e a permanência do jovem no sistema de ensino; promover sua integração à família, à comunidade e à sociedade; desenvolver ações que oportunizem o protagonismo juvenil; preparar o jovem para atuar como agente de transformação e desenvolvimento de sua comunidade; contribuir para a diminuição dos índices de violência, uso de drogas, DST/AIDS, gravidez não planejada e desenvolver ações que facilitem sua integração e interação, quando da sua inserção no mundo do trabalho (BRASIL, 2001).

Dentre os princípios que norteiam a ação do programa, é importante destacar o protagonismo juvenil, um dos fatores que nos levaram a optar pela análise dessa ação. Este se configura como maneira de "estimular o jovem a construção de sua autonomia, por intermédio da criação de espaços e de situações propiciadoras da sua participação criativa, construtiva e solidária" (BRASIL, 2001:1). De maneira geral, a metodologia do programa pretende oferecer ao jovem vivências concretas de participação em ações comunitárias, como etapa imprescindível para o seu desenvolvimento pessoal e social plenos. Eram destinados recursos para a concessão de uma bolsa mensal no valor de $\mathrm{R} \$ 65,00$ para cada jovem, exigindo-se como contrapartida que o jovem tivesse a freqüência mínima de $75 \%$ nas atividades desenvolvidas e que estivesse matriculado e freqüentando a escola formal. Em Belo Horizonte, o jovem pode permanecer no Programa por até três anos, sendo desligado ao completar 18 anos $^{3}$.

A execução do Programa é de responsabilidade das entidades conveniadas, o que implica contratar os educadores, planejar e desenvolver as atividades, acompanhar, avaliar os jovens e participar das reuniões de formação e planejamento organizadas pela Prefeitura. À Secretaria Municipal de Assistência Social (SMAS) cabe a coordenação e a supervisão do mesmo, além do

3 O processo de recrutamento e encaminhamento dos jovens é realizado por órgãos de assistência da Prefeitura Municipal de Belo Horizonte ou pela entidade parceira, seguindo os critérios de situação de risco e vulnerabilidade social das famílias. 
repasse de verbas e do material de apoio. A Secretaria Municipal de Cultura ${ }^{4}$ disponibiliza "oficineiros" para as mais variadas oficinas de arte e cultura. Já à Secretaria Municipal de Abastecimento cabe fornecer o lanche para os 40 núcleos e à Secretaria Municipal de Esporte responsabilizar-se por possíveis atividades de esportes 5 . Em 2004 foi desenvolvido pela SMAS um processo de formação dos educadores dos núcleos, com encontros mensais onde se discutiam temas relacionados à atuação do Agente Jovem. No entanto, segundo os educadores entrevistados, tais encontros ficaram reduzidos à discussão dos problemas existentes na relação da SMAS e as entidades, restando pouco tempo para uma reflexão das práticas desenvolvidas.

\section{O Funcionamento do Programa Agente Jovem}

\subsection{O contexto dos núcleos}

Coerente com os pressupostos do Programa Agente Jovem, os locais escolhidos para sua implementação caracterizam-se pela vulnerabilidade social e pelos baixos índices de desenvolvimento humano. Em Belo Horizonte, os dois núcleos escolhidos para o desenvolvimento da pesquisa não fogem à regra.

O Alto Pereira ${ }^{6}$ abriga atualmente 8.362 domicílios, com uma população estimada em 29.484 habitantes. A densidade populacional (386 hab/ha) da maior parte dos setores do bairro é considerada muito alta, se comparada a outros aglomerados, gerando uma ocupação desordenada permeada de becos que, na sua maioria, não possuem redes de esgoto. O Programa Agente Jovem funcionava através de um convênio da SMAS com a Associação de Moradores, uma entidade fundada na década de 1980 com longa tradição de mobilização em torno de melhorias para

4 Atualmente Fundação Municipal de Cultura de Belo Horizonte.

5 Segundo os educadores, nem todos os núcleos recebem o lanche e a presença da Secretaria de Esporte é cada vez menor nos diversos núcleos.

6 Os dados de Alto Pereira são parte de um projeto denominado Plano Global Específico, realizado pela URBEL e pela PUC no ano de 2000. 
o bairro. No período da pesquisa, a equipe era formada por dois educadores oriundos do bairro e envolvidos com o trabalho da Associação. Uma delas tinha 32 anos, casada, mãe de duas filhas e estava cursando a graduação em psicologia. Já o outro educador tinha 25 anos, casado e pai de uma filha, atuando no Programa há um ano. Além desses, havia o "oficineiro" de teatro, que havia iniciado as oficinas há dois meses apenas. Ele tinha 51 anos e trabalhava para a Secretaria de Cultura nas oficinas de cultura do Agente Jovem desde 2003.

A Vila 7 de Setembro foi o outro núcleo pesquisado em Belo Horizonte. A Vila é um pequeno aglomerado de casas com ocupação desordenada, situado numa região industrial cercada de bairros populares. Segundo dados da $\mathrm{PBH}^{7}$, a Vila apresenta o menor índice de desenvolvimento humano da região administrativa onde se situa. É composta por um conjunto de becos sem infra-estrutura de saneamento, cuja parte mais adensada está situada embaixo de uma linha de transmissão de energia elétrica. São, em geral, construções de alvenaria, algumas ainda inacabadas, muitas construídas a partir da subdivisão de um mesmo lote entre os membros das famílias. Nesse local, vivem 713 famílias, perfazendo um total de 2709 habitantes.

Na Vila 7 de Setembro, a execução do Programa estava a cargo da Ação Social Técnica - AST - desde $2002^{\circ}$. A equipe era composta por uma coordenadora pedagógica e uma coordenadora local, vinculadas à AST, uma educadora da própria comunidade e uma "oficineira". Essa última, responsável pelas atividades das oficinas de Artes Plásticas, estava vinculada à Secretaria de Cultura. A coordenadora pedagógica tinha 35 anos e era graduada em psicologia. Sua função na equipe era apoiar pedagogicamente os educadores do Agente Jovem. A coordenadora local tinha 28

7 Os dados referem-se ao Relatório Estatístico das Áreas para Implantação do Projeto BH Cidadania da Regional, atualizados em 2001.

8 A AST é uma entidade civil nascida nos movimentos populares em 1979, desenvolvendo desde então uma série de projetos na área de educação profissional de jovens e adultos. 
anos, também formada em psicologia e tinha a função de apoiar as atividades de coordenação e de formação. Já a educadora era uma moradora do local, tinha 25 anos, casada e mãe de uma menina. Ela havia completado o Ensino Médio e atuava no grupo de jovens e na catequese da Igreja Católica.

\subsection{O Perfil dos jovens}

Os dois Núcleos pesquisados eram compostos por duas turmas, um padrão comum aos Núcleos do Programa na Região Metropolitana de BH. No Alto Pereira, ambas as turmas funcionavam no horário da tarde, com 25 jovens cada. Na Vila 7 de Setembro, funcionavam pela manhã e tarde, também com 25 jovens cada. Foram investigadas três turmas, num total de 75 jovens ${ }^{9}$. Com relação à idade, a maior parte dos jovens tinha 16 anos (44,8\%), seguidos de $25,4 \%$ que tinham 17 anos, $16,4 \%$ com 15 anos e 10,4\% com 18 anos. Quanto ao sexo, preponderaram os homens $(67,2 \%)$ em relação às mulheres (31,3\%). Segundo se auto-designaram, $38,8 \%$ são da raça negra e $35,8 \%$ pardos, sendo apenas $13,4 \%$ os brancos. Apenas 3\% declararam ter filhos.

Quanto à escolaridade, 95,5\% dos participantes estudavam em 2004, sendo 56,7\% no Ensino Médio contra 31,3\% no Ensino Fundamental e 4,5\% na Educação de Jovens e Adultos. Entre aqueles que estudavam, todos estavam matriculados em escolas públicas. Apesar do pequeno índice dos que se encontravam fora da escola, é um dado significativo na medida em que a freqüência à escola é uma das condições para a permanência no programa. Em relação à escolaridade da família, a maior parte dos pais desses jovens possuía o Ensino Fundamental incompleto (50,7\% para os pais e $67,2 \%$ para as mães), o que evidencia um avanço significativo na escolaridade das novas gerações. Mesmo persistindo uma defasagem idade/série, pois a partir dos 15 anos todos deveriam estar freqüentando o ensino médio, a realidade

9 Para a realização deste perfil, foram aplicados questionários em 67 jovens, perfazendo $89 \%$ do universo investigado. 
escolar dos jovens do Programa está acima da média da cidade. Podemos constatar que, diferente das gerações anteriores, a escolaridade vem deixando de ser um critério significativo para definir a pobreza no Brasil, que passa a ser definida por outras variáveis no contexto de uma nova desigualdade social, como discutiremos abaixo.

Quanto ao perfil profissional das famílias, destacava-se, entre os pais, o emprego com carteira assinada $(28,4 \%)$ ao lado dos desempregados e autônomos, ambos com 16,4\%. Além disso, 9\% se inserem em empregos informais e 10,4\% são pensionistas. Para as mães, 31,3\% são desempregadas e 19,4\% estão em empregos informais. Entre elas apenas 25,4\% eram empregadas com carteira assinada. Outro dado significativo é o fato da grande maioria dos jovens não participar de nenhum grupo ou ação coletiva de qualquer natureza, realidade comum às três turmas.

Esse rápido perfil nos levaria a caracterizar esses jovens como "excluídos", como o fazem geralmente a retórica dos documentos e projetos oficiais. Porém, tanto Castells (1995) quanto Martins (1997) nos advertem sobre a imprecisão em caracterizálos dessa forma, criticando certo fetichismo da idéia da exclusão, que tende a suprimir as mediações existentes entre a economia e outros níveis e dimensões da realidade social. Para Martins (1997:20) o modelo socioeconômico brasileiro implementa "uma proposital inclusão precária e instável, marginal (...) necessário à mais eficiente reprodução do capital."

Optamos caracterizá-los como jovens pobres, vivenciando formas frágeis e insuficientes de inclusão num contexto de uma nova desigualdade social: a nova desigualdade que implica o esgotamento das possibilidades de mobilidade social para a maioria da população, principalmente para o segmento juvenil (Dayrrell, 2005). São esses os jovens que freqüentam o programa Agente Jovem. 


\section{A dimensão (des)educativa do Agente Jovem: o predomínio da forma escolar}

Através da observação desenvolvida nos dois núcleos, pudemos constatar a existência de uma rotina cotidiana que, apesar de diferentes matizes e ênfases, apresentam aspectos comuns expressando um determinado projeto político pedagógico, um certo modelo de valores, posturas e comportamentos que efetivam uma dimensão educativa. De forma sintética, buscaremos descrever aspectos comuns da forma na qual essa rotina se desenvolveu nos núcleos.

\subsection{A infra estrutura}

No cotidiano do Programa, os jovens são reunidos em um espaço próprio, separado dos outros espaços sociais do bairro, onde passam a desenvolver relações especificas com outros jovens e com um educador durante 3 a 4 horas no dia, relações estas diferenciadas daquelas que vivenciam em casa ou na rua. Os Núcleos não possuíam uma sede própria, funcionando em locais emprestados ou alugados, os quais, mesmo apresentando diferenças em relação ao espaço e aos recursos didáticos disponíveis, eram marcados pela precariedade, o que interferia diretamente nas possibilidades educativas do Programa. Foi comum a reclamação dos educadores diante da morosidade da prefeitura em atender as demandas necessárias além dos atrasos constantes no repasse dos recursos financeiros e de material de consumo.

Em um espaço educativo, a arquitetura, sua estética e a ocupação do espaço físico não são neutros. $\mathrm{O}$ mesmo se pode afirmar sobre os recursos materiais disponíveis. Expressa de alguma forma o projeto político pedagógico, muitas vezes implícito, na proposta que se pretende implementar, pois é o cenário concreto onde se desenvolve o conjunto das relações sociais, ampliando ou limitando as suas possibilidades. No caso do Programa Agente Jovem, a precariedade dos espaços e da infra-estrutura disponível pode ser compreendida como a expressão de um Pro- 
grama "pobre" voltada para os "pobres", coerente com a própria concepção a respeito dos jovens atendidos pelo mesmo, como veremos posteriormente. Expressa uma contradição visível em relação aos objetivos propostos e explica, em parte, os limites da ação educativa implementada nos núcleos do Programa.

\subsection{O cotidiano do Programa}

\subsubsection{As atividades temáticas}

Nos Núcleos pesquisados, a organização do trabalho com os jovens apresentou especificidades. As atividades da turma observada no Alto Pereira aconteciam às segundas, terças e quartas-feiras, das 14 às 17 horas. O educador estava presente no Programa todos os dias, porém na terça-feira era ele quem coordenava a "Atividade Temática", a discussão de temas relacionadas à cidadania. Já nas segundas e quartas-feiras aconteciam as atividades da oficina de teatro.

$\mathrm{Na}$ Vila 7 de Setembro, as atividades eram mais intensas, com encontros quatro vezes por semana, das 13:30 às 16:30, distribuídos da seguinte forma: nas segundas-feiras, aconteciam as Oficinas de Formação Humana, nas terças e quartas-feiras, as Oficinas de Artes Plásticas e nas sextas-feiras aconteciam as atividades de esporte e lazer.

Nos dois Núcleos pesquisados, as atividades temáticas estavam relacionadas, de maneira geral, à transmissão ou debate de temas considerados relevantes para a juventude tais como sexualidade, família, drogas, entre outros, ou mesmo sobre a realidade brasileira, quase sempre englobadas sob a temática da cidadania, um termo que parece abarcar qualquer assunto. Tais temas geralmente eram definidos pelo educador, assim como as dinâmicas utilizadas, mesmo que fosse feita consulta aos jovens algumas vezes. Era muito comum a realização de uma exposição oral, ou o uso de textos, e/ ou trabalhos em grupos com apresentação posterior na forma de sínteses escritas ou cartazes. De forma mais 
esporádica, saíram do espaço para fazer alguma pesquisa na comunidade. Apesar de os educadores afirmarem a existência de um planejamento prévio dessas atividades temáticas, na prática transparecia a ausência de uma preparação anterior, com os diversos temas sendo apresentados sem uma articulação maior entre eles, passando de um conteúdo a outro sem que se percebesse um eixo comum, aparentando ganhar sentido em si mesmos. Essa falta de aprofundamento parece resultar em uma legitimação do senso comum, perdendo-se a oportunidade de uma ampliação da visão dos jovens acerca de certas posturas e valores. Ao mesmo tempo, apesar de uma certa preocupação em ouvir os jovens com relação às temáticas que gostariam de discutir, isso não garantia o envolvimento dos mesmos nas atividades propostas que, muitas vezes, transformavam-se em palestras, com um desinteresse visível do grupo, gerando uma sensação de estarem cumprindo uma obrigação, como na escola formal.

O tempo tendia a ser controlado pelo educador, dividido de acordo com a atividade que estava sendo proposta. Durante esse tempo, ele tentava controlar os corpos, impedindo que se deslocassem pela sala ou mesmo saíssem dela, fato que só ocorria depois de uma prévia licença. Controlavam também as interações, insistindo que fizessem a atividade pedida e não se dispersassem com outros assuntos. Sempre havia o controle da presença através da chamada ou da assinatura da lista de presença. Mesmo assim, persistia um clima ameno, com constantes brincadeiras entre os jovens. Durante toda a observação não houve nenhum conflito mais sério nesses grupos, nem mesmo críticas por parte dos jovens. Nas entrevistas, eles destacaram, em sua grande maioria, não tanto os conteúdos discutidos, mas as aprendizagens com relação a valores ("responsabilidade", "respeito", "compromisso", "tolerância"), à postura ("ouvir", "respeitar"), bem como à sociabilidade ("trabalhar em grupo", "vencer a timidez", "falar em público", "ler em público", "ser mais comunicativo", etc.). 


\subsubsection{As atividades de arte e cultura}

Nos dois Núcleos, durante o período da observação, estavam sendo oferecidas oficinas de cartonagem e teatro, coordenadas por profissionais contratados pela Secretaria Municipal de Cultura. Tais oficinas de arte-cultura eram substituídas semestralmente e quase sempre não obedeciam à demanda dos jovens, mas sim à disponibilidade dos profissionais da Secretaria de Cultura. Esse fato gerava desencontros de interesses e expectativas que afetavam o desenvolvimento das oficinas, como aconteceu nos dois Núcleos onde os jovens haviam demandado outra oficina que não aquela que foi oferecida.

No caso da Vila 7 de Setembro, os jovens em geral participavam das atividades de cartonagem, mas havia níveis diferenciados de envolvimento. As moças tendiam a se envolver mais, cumprindo todas as tarefas solicitadas com mais dedicação. A grande maioria dos rapazes, no entanto executavam as atividades como uma obrigação, muitas vezes usando esse tempo para brincadeiras. No Alto Pereira, apenas um pequeno grupo se envolveu de fato com o teatro, com a grande maioria demonstrando tédio diante das atividades sugeridas ao longo do semestre.

A postura dos oficineiros na condução das atividades de arte/cultura pareceu interferir na relação que os jovens estabeleciam com as oficinas. Nesse caso, deve-se levar em conta que esses profissionais eram contratados através de projetos apresentados diretamente na Secretaria de Cultura sem uma relação direta com a comunidade onde os cursos eram desenvolvidos, além de não acontecer reuniões entre técnicos, educadores e oficineiros. O fato de não compreender o universo sócio cultural dos jovens criava um distanciamento entre os sujeitos, exigindo do oficineiro um esforço para se aproximar dos jovens, o que nem sempre ocorria.

Segundo nos relatou a educadora, muitas vezes os conflitos eram alimentados também por um desejo de perfeição. Nesse caso, 
da Vila 7 de Setembro, havia um claro choque de expectativas. A oficineira pretendia que os jovens dominassem a técnica da cartonagem em si, com seus termos técnicos e habilidades. Além disso, pudemos constatar nas diferentes oficinas de arte e cultura uma transposição do universo escolar, suas práticas e posturas, para as experiências educativas proporcionadas a esses jovens no âmbito do Programa. As oficinas tornavam-se verdadeiras "aulas", que não sensibilizavam ou envolviam a maioria dos jovens. Geralmente as atividades consistiam em explanações dos oficineiros ou leitura de textos, individualmente ou em grupo. A ordem dos conteúdos parecia obedecer a uma determinada seqüência de técnicas consideradas necessárias para a aprendizagem, que eram exercitadas posteriormente. Ambas as turmas vivenciaram momentos de tensão entre os oficineiros e os jovens, que demandaram a intervenção dos coordenadores.

Essas questões nos fazem tecer algumas considerações. Primeiramente, o fato de que há uma tendência a transferir para o campo da cultura e das artes um poder quase natural para envolver os jovens e apresentar-se como uma válvula de escape para problemas sociais mais amplos, além de ser uma forma de "ocupar" o tempo dos jovens. Essa tendência pode ser observada também na atuação de ONGs nas periferias, cuja grande maioria desenvolvem atividades ligadas à arte e à cultura. Em segundo lugar, há o fato de que os jovens não atribuem um valor às oficinas meramente pelo fato de se tratarem de temas vinculados à arte e à cultura. Temos de levar em conta que nem todos os jovens estavam ligados ou se mostravam interessados pelas diferentes expressões artísticas e, mesmo quando estavam, estas pareciam não atender às suas expectativas. Como experiências educativas, as oficinas dependem da mediação dos sujeitos e da construção de sentidos pela relação que eles estabelecem entre si. Para os jovens, provavelmente, as oficinas eram apenas oportunidades de experimentação de outras linguagens expressivas e de encontrarem-se com outros jovens em situações diferentes. Para os oficineiros, pelo contrário, havia uma expectativa de for- 
mação técnica e, até mesmo, moral pelo exercício artístico. Por último, é necessário ressaltar, como já destacado anteriormente, a tendência observada nos Núcleos de transposição da lógica e das práticas escolares para o âmbito do Programa.

Descrito dessa forma, é visível que as atividades educativas do Programa Agente Jovem expressam uma adesão tácita a aspectos da lógica escolar, mesmo não sendo essa a intenção dos educadores e oficineiros. Tanto é que muitos jovens referiram-se ao Programa como "curso" ou não perceberam muita diferença entre o Programa e a escola. Parece que os educadores não viam nem concebiam uma outra relação com os jovens além dessa forma escolar, evidenciando a hegemonia desse tipo de relações nas atividades desenvolvidas com os jovens. O que pode significar o fato de atividades educativas que ocorrem fora da escola reproduzirem a sua lógica, sua forma? Se não é uma opção intencional dos educadores, por que isso ocorre? Quais as implicações no processo educativo desenvolvido com os jovens?

\subsection{O Programa Agente Jovem como expressão da forma escolar}

Para desenvolver essa análise, nos baseamos na teoria da forma escolar, que pode fornecer elementos para problematizar esta realidade. Em recente artigo, Guy Vincent, Bernard Lahire e Daniel Thin (2001) defendem a idéia de que na França, como no Brasil, vem ocorrendo uma predominância da forma escolar nos processos de socialização das crianças e jovens. Constatam a existência de numerosos elementos e traços da forma escolar, em diversos graus, nas práticas socializadoras das famílias, e no conjunto de atividades oferecidas às crianças e jovens além do horário escolar. Segundo os autores, "nossa sociedade está escolarizada, incapaz de pensar a educação a não ser segundo o modelo escolar, até mesmo nos domínios alheios ao currículo consagrado das escolas de cultura geral ou de formação profissional"' (2001, p. 39). 
Ao problematizar essa realidade, os autores argumentam sobre a existência de um modo escolar de socialização que veio se tornando hegemônico ao longo da modernidade. Para eles, veio ocorrendo a emergência e consolidação do que eles chamam de uma "forma escolar", que se caracterizaria por um conjunto coerente de traços: a constituição de um universo separado para a infância e juventude; uma forma própria de relação social entre um especialista, um "mestre" e um aprendiz, um "aluno"; a importância das regras na aprendizagem; a organização racional do tempo; a multiplicação e a repetição de exercícios, cuja única função consiste em aprender e aprender conforme as regras, tendo por fim seu próprio fim (Lahire et alii, 2001).

Os autores evidenciam que esta forma escolar, e o modo de socialização que ela instaura, teve uma emergência histórica com o surgimento da escola, nos moldes que hoje conhecemos, a partir do século XVI, com ligações profundas entre a instituição escolar nascente, a cultura escrita e as formas de poder. A escola veio se constituindo como um espaço específico, separado de outras práticas sociais; a escolarização das relações sociais de aprendizagem passa a ser indissociável de uma escrituralização-codificação dos saberes e das práticas, o que torna possível uma determinada sistematização do ensino; a escola passa a ser um dos lugares da aprendizagem de formas próprias de exercício do poder e a instituição escolar passa a ser "O lugar" de aprendizagem da língua, principalmente da escrita, que se converte na condição de acesso a qualquer tipo de saber escolar. Enfim, "a forma escolar de relações sociais é a forma social constitutiva do que se pode chamar uma relação escritural-escolar com a linguagem e com o mundo" (Lahire et alii, 2001:34). Até chegar aos nossos dias, o modo escolar de socialização, ou seja, a socialização pensada e praticada como "educação", se impôs como referência, consciente ou não, como o modo de socialização reconhecido por todos, legítimo e dominante, difundido nas diversas instâncias de socialização. É essa hegemonia que naturaliza a forma escolar como a única for- 
ma possível de estabelecer relações e informar a estruturação de atividades voltadas aos jovens, o que pode explicar a lógica do funcionamento do Programa Agente Jovem.

\subsubsection{Os projetos sociais e a forma escolar}

É importante ressaltar que a presença da lógica escolar em ações desenvolvidas com jovens não é privilégio do Programa Agente Jovem. É possível apreender essa mesma lógica em grande parte das atividades que vêm sendo desenvolvidas com crianças e jovens nas periferias, por ONGs ou projetos públicos, mesmo naqueles em que não teriam uma relação direta com a escolarização. Em uma pesquisa desenvolvida em um projeto sócio educativo existente em uma favela de Belo Horizonte, Bergo (2005:170) também constatou que

no modelo de socialização presente nas oficinas sócio educativas do Projeto Reiventando a Escola, tem predominado uma série de aspectos característicos da instituição escolar(...)que impede a almejada intensificação do diálogo entre os sujeitos e uma melhor compreensão de seus modos de interpretar o mundo.

Nesse e em outros projetos sócio educativos, é muito comum constatarmos essa tendência de transmissão de conhecimentos codificados, mesmo nas atividades que se utilizam das diferentes linguagens artísticas, que ocorrem sob a autoridade de um especialista, com uma progressão programada sob forma de seqüências sucessivas, nas quais a repetição, o respeito pelas regras, são considerados essenciais. Como constata Bergo: "foi possível verificar que, mesmo em atividades tão diversificadas, como as oficinas de flauta, balé ou percussão, a presença de traços característicos do modo escolar de socialização" (2005, p. 179).

O mesmo ocorre com o esporte, uma atividade que seria mais espontânea e distante da lógica escolar. É possível perceber uma disseminação cada vez maior "escolinhas" onde especialistas de "educação esportiva" impõem um "currículo", com um mínimo 
de disciplina e regras na aquisição das técnicas. Sem considerar inúmeros projetos e entidades que propõem atividades de "reforço escolar", nas quais as exigências e as práticas escolares são, de alguma forma, retomadas pelos educadores. Ou ainda, nas ações voltadas às famílias, nas quais é comum o objetivo de "educálos" através de reuniões de formação, abordando temas como higiene, alimentação, drogas, etc. Enfim, parece haver um processo de escolarização do social, uma verdadeira pedagogização das relações sociais.

Uma das conseqüências de tal hegemonia pode ser constatada na forma como se estabelecem as relações geracionais, no nosso caso, com os jovens. Como evidenciamos anteriormente, através da descrição do Programa Agente Jovem e nos outros exemplos dados, qualquer relação ou atividades dirigidas aos jovens, principalmente das camadas populares, tende a ser estruturada na ótica da educação, concretizada em práticas pensadas e pretendidas como educativas. Há uma tendência em transformar cada instante em instante de educação, cada atividade, em uma atividade educativa, ou seja, como uma atividade cuja finalidade é formá-los, formar seus corpos, formar seus conhecimentos, formar sua moral, enfim, "civilizá-los". Como se não existisse outra forma de estabelecer relações, como se não existisse outra forma de estruturar atividades que não na forma escolar.

Quais as implicações que tal lógica gera na formação humana dos jovens, principalmente aqueles das camadas populares? Em que medida tal lógica contribui na formação dos jovens como sujeitos autônomos? Esse é um debate fundamental a ser desenvolvido tanto pelos órgãos públicos quanto pelas entidades da sociedade civil que desenvolvem ações voltadas para a juventude colocando em questão tanto a forma como as concepções que compõem tais ações.

Ao mesmo tempo, é necessário pontuar a ênfase dada aos conteúdos ligados à cidadania. Como afirma Sposito (2005:28), ao analisar programas de transferência de renda, 
a ênfase dada a essa dimensão acaba por fazer emergir um conceito de cidadania muito mais ligado a uma idéia de atividade educativa intencional, marcada pelo civismo ou, em uma versão mais amena, pela absorção de valores ligados à civilidade que seriam expressão de um programa civilizador não cumprido pela instituição escolar. Trata-se mais de ensinar do que de praticar as virtudes da cidadania, deslocando-se o foco das práticas para a ação intencional e sistemática, veiculada, principalmente, pela transmissão de alguns conteúdos.

Alerta, ainda, a autora que neste enfoque corre-se o risco de esvaziar os conteúdos inscritos na idéia de direitos.

Para ampliar a reflexão sobre a natureza sócio educativa das ações públicas dirigidas a jovens pobres nas periferias das metrópoles brasileiras, buscaremos, em seguida, analisar, na ótica dos jovens, as relações do Programa com a escola, a participação juvenil no Programa, a transferência de renda, bem como as relações sociais que se estabelecem no seu cotidiano.

\subsection{O programa Agente Jovem e a Escola}

O Programa Agente Jovem focaliza, em seus objetivos específi$\cos$, a reinserção e a permanência do jovem no sistema de ensino formal. Porém, no cotidiano do Programa constatamos que as questões relacionadas com a escola eram pouco tematizadas e não havia praticamente articulação com as escolas freqüentadas pelos jovens. Pode parecer um paradoxo, mas podemos perceber que, se de um lado há uma hegemonia da forma escolar presidindo a lógica da organização e funcionamento do Programa, por outro lado, existe um distanciamento da escola real, interferindo pouco no percurso escolar desses jovens, marcados pela precariedade comum à escolarização das crianças e adolescentes das camadas populares.

Nos dois núcleos, a escola nunca foi tematizada de maneira 
mais sistemática durante o período da observação, a não ser em falas "soltas" dos educadores sobre sua importância como lugar de aprendizagem, incentivando os jovens a estudar. Em um deles, havia a prática do acompanhamento da freqüência dos jovens, através de relatórios mensais que a escola enviava. Mas isso não impedia a existência de jovens infreqüentes ou que abandonaram a escola naquele ano.

Nas entrevistas, os educadores reconhecem a inexistência de uma relação mais próxima entre o Programa e a escola dos participantes, ficando evidente que para eles a escola é um espaço distante, que apresenta inúmeras barreiras para uma maior articulação. Ao mesmo tempo, percebem a importância da criação de uma rede social, na qual a escola e o Agente Jovem poderiam trabalhar juntos. Essa realidade evidencia que a relação do Programa com a escola não se constitui como uma orientação prioritária para os seus gestores, sendo, na prática, uma opção de cada um dos núcleos.

É importante refletir também em que medida a freqüência ao Programa interfere de alguma forma na vivência escolar. Segundo os jovens, percebe-se que a participação que tiveram não interferiu de forma significativa nos percursos escolares, quase sempre vista como uma obrigação necessária. Alguns deles apontaram algumas mudanças geralmente vinculadas à postura na sala de aula ("concentração", "capacidade de trabalhar em grupo", "falar mais") e ao envolvimento com as tarefas escolares em geral ("estudar mais", "envolvimento"). Alguns jovens enfatizaram uma mudança na postura individual em sala de aula, marcada pelo melhor convívio com colegas e professores.

Nota-se que, no ponto de vista dos jovens, um dos principais impactos do Programa se refere ao desenvolvimento de habilidades, como a expressão verbal, a convivência coletiva, que deveriam estar sendo desenvolvidas na escola. Entretanto, podemos constatar que, de forma geral, não há um maior impacto do Programa na instituição escolar, muito menos no percurso es- 
colar dos jovens. Uma série de estudos ${ }^{10}$ que analisam a relação da juventude com a escola, principalmente das parcelas enquadradas nas condições de "vulnerabilidade social", como são os jovens participantes do Programa, constatam uma ampliação do acesso à escola, mas que não vem sendo acompanhada pela ampliação da qualidade dos processos educativos oferecidos, avançando pouco no sentido de constituir novas práticas educativas, estruturas e projetos pedagógicos que respondam aos anseios e desafios que estão postos para a educação da juventude. Nesse sentido, o Programa, mesmo se efetivamente exigisse o retorno à escola, apenas sinaliza a permanência dos mesmos processos de exclusão, pouco interferindo na real interação que os jovens mantêm com a instituição escolar. Ao mesmo tempo, a falta de políticas universais (educação, saúde, segurança, etc.) de qualidade impacta também o Programa. A falta de uma boa escola, por exemplo, interfere nas possibilidades de sua atuação, responsabilizando-o por uma dimensão para a qual também não tem resposta. Isto é, há um círculo vicioso de um programa precário para uma escola precária e vice-versa.

\subsection{A participação social e o protagonismo dos jovens}

Um dos objetivos do Programa é a participação ativa do jovem na comunidade a partir de uma percepção do mesmo como agente transformador. Segundo as suas diretrizes, a atuação na comunidade é vista como uma contrapartida à participação no Agente Jovem. Ela tem como finalidade, além do aspecto formativo, contribuir para a melhoria dos indicadores sociais locais. Tal participação concretiza a concepção de "protagonismo juvenil" compreendido como a capacidade do jovem em construir sua autonomia a partir da criação de espaços e situações propiciadoras da sua participação criativa, construtiva e solidária (Brasil, 2001).

10 Sposito, 2005; Corti e Souza, 2004; Souza, 2003, entre outros. 
Desde meados da década de 1990, a noção de protagonismo juvenil vem sendo cada vez mais utilizada por gestores públicos, lideranças comunitárias, professores e/ou educadores ligados a ONGs, além de estar sempre presente nas justificativas de projetos voltados para a juventude. Há uma tendência em tomá-la como um conceito unívoco, como se ao falar "protagonismo juvenil" estivesse se referindo a um aspecto universal da realidade juvenil, sendo entendido como uma característica inata da juventude, como se fosse uma dimensão inerente ao jovem. Será que o fato de ser jovem, em si, implicaria em uma postura de liderança, de adesão a uma ação transformadora?

Geralmente, quando se fala em protagonismo juvenil, fazse menção a uma proposta na qual o jovem assuma um papel central na comunidade e/ou em um determinado projeto, e genericamente, em um desejado processo de mudança social. Mais do que um princípio ético político, refere-se a um objetivo que se quer alcançar quando se desenvolvem ações para ou com a juventude, ou a uma escolha de uma metodologia de trabalho com os jovens. Ou seja, é mais uma proposta do mundo adulto para os jovens, uma postura metodológica ou mesmo uma estratégia educativa do que uma característica própria da juventude como uma fase da vida. Sendo assim, o conceito em si não é auto-explicativo. O mesmo enunciado pode estar se referindo a objetivos e posturas metodológicas muito diferentes, demandando que na sua utilização sejam explicitados os pressupostos, as estratégias e meios utilizados para que se efetive como tal. Como lembra Sposito (2003:65), o termo tem sido utilizado de forma pouco crítica e, muitas vezes, "parece tratar-se de mais uma metodologia de ação com o trabalho dos jovens do que um principio ético-político que pressupõe o reconhecimento dos jovens como atores coletivos relevantes e, por isso mesmo, com direito à autonomia"

É o que parece ocorrer com o Agente Jovem. Nele, a noção de protagonismo está associada a uma ação dos jovens na comunidade de origem. Nos núcleos pesquisados, tal participação se 
dava através de reflexões sobre os problemas locais e, em um deles, complementadas através de pequenas ações de intervenção local. De uma maneira geral, havia por parte dos educadores uma postura de incentivar a participação dos jovens em atividades comunitárias. No entanto, enquanto na sua formulação o Programa Agente Jovem insistia na participação como um objetivo central, faltava estrutura para que os jovens pudessem efetivamente participar, principalmente no que tange aos custos de alimentação e transporte.

Nas entrevistas, os jovens evidenciaram o desenvolvimento de um olhar mais sensível para a comunidade, numa mudança de percepção em relação ao lugar onde moravam. Pelo que foi possível apreender, o principal impacto do Programa em relação à comunidade foi o de despertar em alguns jovens o desejo de participação, o que não resultou necessariamente em um engajamento de fato. Não foi possível perceber entre os jovens pesquisados a existência de lideranças juvenis ou de jovens engajados concretamente em alguma ação coletiva. Nem mesmo uma compreensão mais elaborada das relações de poder no âmbito local, muito menos dos mecanismos de decisões municipais. É necessário ressaltar também a ausência de uma abertura para outras formas de participação juvenil. Além do Alto Pereira, não foi constatada uma atitude ou intenção por parte dos educadores em articular os jovens com iniciativas existentes nas diferentes regiões ligadas a grupos culturais, por exemplo. Imerso na lógica da forma escolar, parece ser difícil aos educadores desenvolverem ações onde os jovens exerçam efetivamente um protagonismo, desde na definição das possíveis ações a serem desenvolvidas, a partir dos seus reais interesses, até na sua implementação, respeitando seus ritmos e tempos.

\subsection{A transferência de renda: os jovens e a bolsa}

Como já apontado anteriormente, o Agente Jovem concede aos jovens inseridos nas atividades e freqüentes um benefício finan- 
ceiro mensal no valor de 65,00 reais com o objetivo de criar condições para que eles permaneçam na escola e se preparem para o mundo do trabalho. Cabe perguntar quais as implicações dessa política que transfere renda diretamente para os jovens.

Associada a outras motivações -a possibilidade de aprender algo, o incentivo dos pais e o desejo de ocupar o tempo de alguma forma- a bolsa era um incentivo para os jovens se inscreverem e se manterem no Programa. A grande maioria deles afirmou ter entrado no Programa, em primeiro lugar, por causa dessa bolsa.

Um primeiro aspecto a ser analisado refere-se às implicações dessa bolsa para as famílias desses jovens, tendo em vista que são pobres, com renda per capita de até meio salário mínimo. De uma maneira geral, os jovens dividem o valor da bolsa com a família, fato que é visto com naturalidade, como um valor, uma retribuição moral. Parece haver um sentimento de obrigação em contribuir no sustento da casa, indicando um aspecto central nas relações dos membros das famílias das camadas populares, já constatado em inúmeras pesquisas. Essas relações estão, em grande parte, baseadas em estratégias de sobrevivência, com todos os membros colaborando para o sustento do núcleo familiar. Muitos jovens ressaltaram que a bolsa interferiu nas relações familiares, pois passaram a contar com maior reconhecimento por parte dos pais e se sentiram mais independentes. $\mathrm{O}$ fato de não precisar pedir dinheiro aos pais para as suas atividades possibilitava o exercício da autonomia pessoal, o que facilitava as relações no âmbito doméstico.

Já o valor reservado para o jovem tinha os mais variados destinos: o utilizavam para pagar cursos (teatro, forró, informática), para adquirir o material escolar (livros, cadernos, xerox) ou para financiar atividades de lazer (cinema, lanches, transporte, etc.), entre outras destinações. Esse amplo uso da bolsa parece produzir um importante impacto na vivência juvenil. Primeiramente, porque permite consumir bens próprios da sua geração, 
como CDs, roupas e acessórios. Além disso, há uma facilitação do convívio com outros jovens, pois possibilita que o jovem passe a freqüentar festas e eventos sem necessitar da colaboração dos colegas ou dos pais. Mesmo com um valor irrisório, a bolsa parece ampliar as possibilidades de vivência da própria condição juvenil.

Além disso, a bolsa parece proporcionar um exercício de escolha nas decisões sobre o que comprar e onde gastar. Para muitos dos jovens, lidar com o dinheiro possibilitava o exercício da autonomia como um valor, residindo aí também uma dimensão educativa. Ao mesmo tempo, é preciso levar em consideração que a bolsa dos jovens, no período em que a pesquisa estava sendo realizada, atrasava constantemente. Esse atraso gerava desconfiança e tensão entre eles. Tal realidade, além de revelar a precariedade de funcionamento do Programa, criava empecilhos à própria vivência da condição juvenil para esses participantes, uma vez que limitava a sua participação efetiva no mercado de consumo e nas formas de lazer.

Dessa forma, levando-se em consideração o baixo valor da bolsa e os atrasos constantes, podemos dizer que, como política social de transferência de rendas, o Agente Jovem está distante de promover as condições adequadas para uma inserção social e profissional dos jovens, diferente daquela dos seus pais e irmãos.

\subsection{As relações sociais no Programa}

Um aspecto que chamou atenção nos Núcleos pesquisados foram as relações positivas dos jovens entre si, marcadas por um clima de respeito e diálogo. Apesar da precariedade quanto às condições de trabalho (infra-estrutura inadequada, falta de material de consumo, atrasos dos recursos financeiros, etc.) e da aparente falta de sentido para algumas atividades realizadas, como já descrevemos anteriormente, havia uma valorização do Programa por parte dos jovens como um espaço de encontro e convivência. 
Nos contatos e nas entrevistas com os jovens do Alto Pereira, por exemplo, foi muito enfatizada a importância do espaço de convívio, da interação com outros jovens, a ampliação das amizades e a relação de confiança com o educador. Fica claro que esses jovens valorizam o Programa como experiência de vivência coletiva: "Porque antes eu convivia menos, com menos pessoas" (D., mulher, 16 anos, Alto Pereira).

Os jovens parecem valorizar no Programa a dimensão da convivência cotidiana, do encontro com os pares. Esse aspecto torna-se mais importante se levarmos em conta a realidade das periferias de Belo Horizonte, nas quais praticamente não existem ofertas de espaços e equipamentos de lazer que promovam o encontro entre os pares. Como nos diz um deles: "Eu só ficava naquela coisa de ir prá escola e de lá pra casa, entendeu? Variava muito pouco, entendeu?" (E, 17 anos, Alto Pereira)

Nesse sentido, o Programa aparece para os jovens como um lugar onde se ocupa o tempo, mas também encontram outros jovens, apontando para a centralidade das relações grupais e da sociabilidade no processo de formação humana dos mesmos. Esses jovens se encontram na sua maioria na adolescência, a porta de entrada na juventude, um período marcado pela ampliação das experiências de vida, quando começam a se descobrir como indivíduos. Passam a ter mais autonomia para sair de casa à noite e a escolher as formas de diversão. É quando o jovem tende a romper com tudo aquilo que o prende ao mundo infantil, buscando outros referenciais para a construção da identidade fora da família. É um momento próprio de experimentações, de descoberta e teste das próprias potencialidades, de demandas de autonomia que se efetivam no exercício de escolhas. É um processo que tem uma dimensão espacial demarcada, como o bairro, as ruas e as ofertas de lazer existentes, quase sempre limitadas e precárias, que se tornam o cenário em que se desenrolam as relações. A turma de amigos cumpre um papel muito importante nesse processo. 
Nesse sentido, o Programa, mesmo que de uma forma não intencional, difusa, já que não consta dos seus objetivos, cumpre uma função educativa importante ao possibilitar um leque maior de escolhas para a criação do grupo de amigos, em uma ampliação da rede de relações. Não podemos esquecer que o grupo de pares, o lazer e a diversão aparecem como elementos constitutivos da singularidade da condição juvenil das camadas populares. Segundo Pais (1993:94), os amigos do grupo "constituem o espelho da sua própria identidade, um meio através do qual fixam similitudes e diferenças em relação aos outros."

\subsubsection{A relação dos jovens com os educadores}

O perfil e a postura dos educadores parecem interferir muito para ampliar ou limitar essa dimensão da sociabilidade, bem como no desenvolvimento das ações educativas. E estas são informadas pela concepção que possuem a respeito dos jovens. Podemos afirmar que a maneira como o educador enxerga os jovens é, em grande parte, determinante da maneira como ele se relaciona com os mesmos e busca educá-los. Essa realidade ficou patente nos núcleos pesquisados principalmente nas diferentes posturas dos educadores e dos oficineiros.

No caso dos educadores, tanto na Vila quanto no Alto Pereira, foi perceptível a existência de uma relação muito amigável entre educadores e jovens. $\mathrm{O}$ fato de os educadores residirem no local, compartilharem da mesma origem e do mesmo contexto sócio-cultural, além do envolvimento comunitário, mostrou-se muito positivo, pois contribuía na construção de relações mais próximas entre jovens, educadores e suas famílias, fortalecendo o compromisso dos participantes com o Programa. Essa postura parece revelar um esforço em superar a hierarquia, as relações verticalizadas, típicas da forma escolar. Não é de se estranhar que alguns jovens façam um contraponto entre o clima das relações no Programa e na escola:

Os professores não quer nem saber de você. Aqui não. 
Aqui você pode chegar, você conversa com a A, você conversa com a $C$. Você pode falar que tem aqui uma coisa que você não tá gostando. (F, homem, 16 anos, Vila)

Os jovens contrapõem o universo tenso das relações entre professores e alunos, comuns na escola, ao clima de respeito e compromisso que marca a atuação dos educadores na turma da Vila. Muitos se referiram à postura de ouvir ("eles ouvem"), ao envolvimento e também à postura de "chamar a atenção" quando havia algum problema em relação à participação de algum deles.

Tanto na Vila quanto no Alto Pereira, o discurso dos educadores tendia a uma valorização dos jovens como sujeitos, concretizado nas relações que estabeleciam, na postura de escuta e em um discurso baseado no estimulo à autonomia dos jovens nas atividades que desenvolviam, apesar da compreensão restrita que tinham sobre esse valor e a forma de implementá-lo de fato.

Por outro lado, os oficineiros dos dois núcleos revelaram uma visão mais próxima do senso comum acerca dos jovens pobres, tendendo a ressaltar aspectos negativos. No caso da Vila, a visão manifesta da oficineira tendia a ressaltar os jovens pobres como um problema social e vê-los como sujeitos a serem recuperados ou objetos de uma ação preventiva, particularmente calcada na idéia de que o principal objetivo do programa seria "ocupar o tempo ocioso" e "tirar os jovens da rua". Na turma da Vila, vários depoimentos revelam essa dificuldade de relacionamento entre a oficineira e os jovens:

...a maioria das pessoas não gostou dela porque ela é muito diferente da gente. Por causa da classe dela, que ela foi criada, né? Ela não consegue entender a gente não. (F, homem, 16 anos, Vila)

Esse jovem refere-se a uma dimensão fundamental em qualquer processo educativo que é a necessidade de conhecer o Outro 
como condição para a compreensão das suas atitudes e valores. Como nos lembra Brandão (1985:138): "conhecer não apenas o mundo cultural da crianza (e do jovem) mas a vida da criança (e do jovem) em seu mundo de cultura"11.

Da mesma forma, na percepção do oficineiro do Alto Pereira, destacava-se o enfoque do "jovem problema", para o qual é preciso soluções que o "reintegrem" à sociedade, evitando que se transforme em um risco. Os beneficiários do Programa são os jovens de setores excluídos, ou seja, os mais propícios a condutas delinqüentes. Tal elaboração contribui para o fortalecimento de um estigma da condição juvenil (principalmente da periferia) já bastante arraigada no imaginário social e difundida pelos meios de comunicação. Informados por tais concepções, não é de se estranhar que as atividades das oficinas, embora com diferentes matizes, foram mais conturbadas e com momentos de tensão entre os envolvidos, diferente das atividades desenvolvidas pelos educadores.

Tais concepções não são muito diferentes daquelas presentes na formulação do próprio Programa. O uso de conceitos como "situação de risco" e "vulnerabilidade social", associada à idéia de ocupação do tempo ocioso, acaba por reforçar uma representação do público-alvo como "problema" e "risco social", principalmente no que tange ao uso do tempo livre. Essa abordagem dos jovens pobres tem sido recorrente nas políticas públicas dirigidas a esse público, partindo-se de uma visão estereotipada dos jovens como "problema social" em contraposição à visão dos jovens como "sujeitos de direitos".

Ao mesmo tempo, chamou a atenção o fato de que os próprios jovens parecem assimilar e reproduzir estas elaborações negativas sobre a juventude:

11 Em parenteses, complementos nossos. 
Ah também é bom, pra gente, a gente fica menos tempo na rua aprendendo o que não presta e fazendo o que não deve. (J, homem, 16 anos, Alto Pereira)

$\mathrm{Na}$ avaliação do programa pelos jovens, esses parecem incorporar, pelo menos diante dos pesquisadores, parte dos pressupostos que orientam a concepção do Programa, revelando uma certa adesão ao modo como os adultos os vêem. A definição "proposta de ocupação" enunciada no programa, pode ser lida como proposta de controle social do tempo livre, como forma de combater problemas sociais que envolvem jovens, em um limite tênue entre cuidado, controle e contenção. O que vemos nas falas de muitos deles, quando falam da importância do Agente Jovem, é também uma percepção da juventude como segmento que parece estar mais propício a situações de desvio, principalmente quando os jovens têm tempo livre. É necessário questionar que tal "preocupação com o tempo livre da juventude não pode se limitar à busca de redução de danos ou de prevenção da violência, mas, fundamentalmente, considerar as potencialidades impressas na vivência plural do tempo livre, do lazer e da cultura como direitos plenos de cidadania" (Brenner et Alii, 2005:213).

Ao mesmo tempo, precisamos levar em conta que, para esses jovens há poucas possibilidades de vivência desse tempo livre. Faltam alternativas de lazer, as praças existentes estão mal cuidadas, não há campos ou quadras de esporte, centros de informáti$\mathrm{ca}$, lugares que possibilitariam encontros e trocas entre as pessoas. Vivemos numa lógica econômica e social excludente, que atinge principalmente os jovens e lhes nega oportunidades de vivência de experiências sociais e culturais significativas. Muitos espaços estão fechados para eles.

No imaginário social, são recorrentes as associações entre o tempo livre do jovem, o ficar na rua e o desvio. Ao mesmo tempo, não se pode desprezar a realidade que também se impõe naquele lugar, ou seja: o tráfico de drogas e o aliciamento de jovens são 
condições que se efetivam. E as concepções correntes reforçam essa visão negativa que passa a ser naturalizada ou inquestionável. Mesmo nas visões de jovens participantes, vimos como o tempo livre aparece de forma negativa, possibilitando o envolvimento com a criminalidade, e não como tempo de lazer, por exemplo.

O próprio caráter compensatório do Programa pode ser visto como fruto de uma visão limitada acerca da juventude contemporânea. Esse caráter se revela, entre outras manifestações, na ausência de investimentos públicos em infra-estrutura, materiais de consumos, qualificação dos profissionais, etc. Se a lógica é ocupar o tempo, afastando os jovens da rua, parece que os conteúdos das atividades pouco importam, pois o simples fato de ocupar o tempo já representa a ação do Programa. Como relata um dos jovens:

Mas só o fato de saber que tem, no caso, aqui são cinqüenta, tem cinqüenta jovens que estão livres desses problemas das drogas, da violência já é um grande alívio. Porque poderiam ser cinqüenta que estariam lá fora talvez hoje nem estariam vivos. (A., mulher, 17 anos, Alto Pereira)

A concepção da juventude como um problema social estava presente no Agente Jovem nos discursos dos participantes, evidenciando conexão e aproximação entre representações normativas e de senso comum. Assim, a tematização da juventude pelo senso comum, disseminada nos meios de comunicação e assumida pelas políticas públicas, podem estar reforçando percepções estereotipadas dessa faixa etária.

\section{Considerações finais}

A descrição e analise do Programa Agente Jovem levanta uma série de questões que merecem um aprofundamento. Mais do que conclusões, pretendemos sinalizar temas que merecem um aprofundamento posterior. 


\subsection{O Programa como uma "Pedagogia da Precariedade"}

Uma primeira questão refere-se à precariedade com que o Programa Agente Jovem vem sendo implementado, numa clara distância entre os objetivos explicitados e a prática cotidiana, o que sinaliza para seu lugar secundário na agenda das políticas públicas na RMBH. Embora relevante do ponto de vista de representar o investimento do poder local em ações especificamente voltadas para a juventude, observam-se muitas dificuldades com relação à estrutura física, aos investimentos na formação dos profissionais e às condições adequadas de trabalho, que interferem diretamente nos impactos que o Programa produz nos jovens que dele participam, limitando a sua dimensão educativa. Um exemplo que salta aos olhos é o fato de as experiências de formação proporcionadas aos jovens serem determinadas em função da capacidade instalada dos órgãos públicos. As oficinas, por exemplo, são definidas a partir da oferta, sem que as demandas apresentadas pelos jovens sejam efetivamente contempladas. Outro exemplo é a falta de recursos didáticos mínimos, como televisão e vídeo, o que limita as possibilidades educativas. Deve-se ressaltar também a descontinuidade existente nas possibilidades de ação dos educadores. Aqueles mais antigos lembram quando a prefeitura fornecia vales transporte para os jovens participarem de atividades fora do bairro, como também a freqüência a cinemas e teatros, o que já não mais ocorreu em 2004. Vem sendo reforçada assim a tendência em confinar os jovens ao próprio bairro, limitando as possibilidades educativas do acesso à cidade com o que ela pode oferecer de ampliação de experiências culturais.

Uma outra expressão da precariedade do Programa é a estrutura física dos Núcleos, sua arquitetura, sua estética e a infra-estrutura disponível. Esses jovens, imersos numa realidade de inclusão precária, sem acesso a equipamentos públicos de informação e de lazer, ao se depararem no cotidiano do Programa com os espaços físicos precários, feios, mal cuidados, sem a infra- 
estrutura e os recursos didáticos necessários, vêem ressaltado o lugar social subalterno ao qual são destinados pelas políticas públicas. O Programa se constitui como um projeto "pobre para os pobres", numa contradição com o discurso dos direitos sociais, da cidadania. Não podemos esquecer, com Paulo Freire (1996), que a "educação, a ética e a boniteza devem andar de mãos dadas", quando se pretende desenvolver uma pedagogia da autonomia $^{12}$.

De toda forma, fica evidente a falta de equipamentos sociais nos bairros de periferia da cidade, como centros da juventude ou mesmo clubes públicos, onde os jovens possam ter acesso a espaços de lazer e sociabilidade, que forneçam recursos e informações que estimulem a criação e a liberdade, possibilitando assim o seu desenvolvimento integral. Ao contrário, porém, e já um reflexo da lógica da "forma escolar", um dos únicos equipamentos públicos existentes nesses bairros são as escolas públicas. Também reflexo dessa mesma lógica, é o fato de o Programa ser desenvolvido em um espaço separado dos outros espaços sociais do bairro. Como na escola, tal prática vem reforçar o risco em naturalizar o lugar dos jovens apenas em espaços separados do mundo social, protegidos, controlados e disciplinados por adultos, e a negação da sua presença nos espaços públicos, vistos como espaços perigosos, da perdição e destruição. Como nos lembra Abramo (2003:234):

Não se pode postular a retirada dos jovens dos espaços públicos, as ruas entre eles, a sua necessidade de circular, de interagir com os outros atores, fora de espaços controlados e disciplinados por adultos. O desafio é pensar de que modo tais centros (da juventude) podem se oferecer como alternativas de espaços sadios para os jovens

12 Mas devemos ressaltar que cada experiência assume contornos diferenciados de acordo com a entidade executora. Aquelas entidades com maior estrutura, como o caso da AST, capazes de buscar outras fontes de financiamento e com um corpo de profissionais estável têm melhores condições de potencializar a ação do programa ao oferecer melhor estrutura e suprir algumas lacunas na ação dos órgãos públicos. 
desenvolverem suas potencialidades, mas não como de confinamento e apartação do mundo social.

Levando em conta tais desafios, podemos questionar se uma política publica para a juventude, ao contrário de pulverizar recursos em programas sócio educativos de baixo custo, marcados pela descontinuidade, não deveria priorizar o investimento em tais equipamentos públicos permanentes. Em suma, parodiando Leão (2003), podemos afirmar que o Programa Agente Jovem se constitui como uma pedagogia da precariedade, bem distante dos objetivos pretendidos, aliada a uma lógica da provisoriedade, não havendo garantias de continuidade das ações desenvolvidas muito menos do próprio Programa, sempre ameaçado de ser extinto.

Um outro aspecto é o significado da bolsa para os jovens. Apesar do seu baixo valor e dos constantes atrasos, a bolsa se constitui como condição da vivência da condição juvenil, tanto no que se refere ao consumo, quanto a um exercício da autonomia. Essa dimensão ficou muito evidente na relação com a família, que abre espaços para uma maior independência e liberdade de ação do jovem e também na ampliação do seu leque de escolhas, podendo decidir minimamente sobre o que e onde investir o pouco que ganha. Barman (1998) já nos dizia que a liberdade de escolha é, no contexto das sociedades contemporâneas, o fator essencial de estratificação social: "escolhe quem pode". Imersos em um contexto sócio cultural marcado pela inclusão subalterna (Martins, 2000), esses jovens vêem reduzidas as possibilidades do exercício da escolha, um pré-requisito básico para a construção da autonomia, interferindo nos processos de sua formação humana. Nesse sentido, a bolsa ganha um significado que merece ser aprofundado. 


\subsection{Os limites e possibilidades da dimensão sócio educativa do Programa}

Uma outra questão a ser refletida refere-se à dimensão sócia educativa do Programa Agente Jovem, discutindo as implicações das atividades desenvolvidas e a proposta do protagonismo juvenil. Embora se pretenda fortalecer a participação e a autonomia juvenil, ainda é muito presente uma visão escolarizada das intervenções educativas, reforçando uma visão dominante de que o jovem precisa ser "educado". Como vimos, a hegemonia da lógica da "forma escolar" leva a considerar que toda a atividade para os jovens tem de ter um caráter educativo, disciplinador, que o jovem não pode ter o tempo livre para processar por si suas buscas e experimentações, que suas atividades devem ser sempre mediadas por adultos com controle sobre suas ações (Abramo, 2003). Podemos constatar que a hegemonia de tal lógica tem deixado pouco espaço para que outras formas educativas sejam reconhecidas e valorizadas. As experiências educativas proporcionadas pelo Programa se mostram tímidas em favorecer a auto-organização dos jovens e criar vínculos com outros agrupamentos juvenis.

Mesmo no interior de uma lógica escolarizada, é possível questionar a qualidade das atividades educativas oferecidas. Pudemos constatar que o conjunto das atividades proporcionadas pelo Programa, incluindo aquelas ligadas às expressões culturais, mostra-se fragmentado, descontínuo, apresentando poucos resultados em termos de aprendizagem dos jovens. Ao mesmo tempo, os educadores não possuem uma formação adequada, um corpo de saberes delimitado, para enfrentar as demandas e os desafios que lhes são postos pelo cotidiano. Além da fraca institucionalidade do lugar que ocupam, com contratos e salários precários, muitos deles pautam-se mais por uma postura individual de boa vontade e compromisso afetivo com os jovens, do que por uma adesão profissional.

Ao mesmo tempo, pelo que foi possível observar, tais atividades educativas, organizadas nessa lógica, com essa precarieda- 
de, vêm possibilitando aos jovens poucas oportunidades do exercício da escolha, da tomada de decisões, elementos fundantes da autonomia. Sem esse exercício da autonomia fica difícil pensar em algum tipo de protagonismo. Podemos constatar assim que a forma como vem sendo estimulada a participação dos jovens no cotidiano do Programa e na comunidade contribuem pouco para o exercício de fato do protagonismo juvenil, nos moldes como está expresso nos seus objetivos.

Por outro lado, um aspecto que nos chamou a atenção foi a importância que os jovens atribuíram às relações sociais entre eles e deles com os educadores locais, apesar dessa dimensão não aparecer como parte dos objetivos do Programa. Tal ênfase vem reforçar a importância do grupo de pares, da sociabilidade nos processos de formação humana dos jovens, apontando para a necessidade de que ela seja valorizada e estimulada enquanto uma dimensão educativa. O mesmo ocorre com a relação dos jovens com os educadores. Do ponto de vista destes, o fato de serem do próprio local, compartilhando de um mesmo contexto sócio cultural, pareceu-nos ser uma variável que contribui nas relações com os jovens, acrescida do fato de todos os educadores se sentirem comprometidos com o destino social dos jovens. Do ponto de vista dos jovens, os educadores significam um contato com o mundo adulto baseado no diálogo, talvez um dos poucos espaços que encontram no qual são respeitados como sujeitos, onde podem falar de si mesmos e dos problemas que os afligem. Nesse sentido, parece ficar claro que o compromisso e envolvimento dos educadores e a sociabilidade existente no cotidiano são um dos poucos pilares que garantem que o Programa tenha um impacto positivo para os jovens.

Finalmente, é importante pontuar um aspecto presente na ampliação de programas sócio educativos nas periferias dos grandes centros, implementados tanto por ONGs quanto pelo poder público, em ações como o Programa Agente Jovem. Há uma tendência em se criar dois sistemas educativos paralelos, o da escola e o dos projetos sócio educativos, que não interagem 
nem dialogam entre si, com críticas mútuas que não contribuem para a superação da precariedade existente nos dois sistemas. Podemos afirmar que está se criando um sistema paralelo precário para combater a precariedade da escola. Tal realidade, ao contrário de contribuir na trajetória escolar dos jovens, pode favorecer "um maior distanciamento da vida escolar, sobressaindo uma relação meramente instrumental que reforça o caráter meritocrático e credencialista da educação escolar" (Sposito, 2005:27).

Enfim, podemos afirmar que o Programa Agente Jovem ainda carece de infra-estrutura, equipamentos, de canais de dialogo e participação, de tal forma a deslocar o foco das ações compensatórias para políticas de construção de espaços públicos que garantam esferas de participação efetivas dos jovens. Na forma como vêm sendo implementado, o Programa aponta para um modelo que enfatiza a dimensão sócio educativa, mas de forma precária, gerando uma tutela do tempo livre do jovem, não atendendo, assim, às suas demandas. É nesse sentido que, ao pensar o Agente Jovem, não basta enfatizar somente a esfera da formação, mas também as esferas da experimentação, da iniciação, da realização, da participação, redefinindo a própria noção de política. Como lembra Reis (2005), a idéia da política precisa ser experimentada de maneira mais ampliada pelos jovens a fim de serem viáveis as transformações culturais no campo das políticas públicas da juventude.

\section{Referêrencias Bibliográficas}

Abramo, Helena (1997). “Considerações sobre a tematização social da juventude no Brasil". Revista Brasileira de Educação. São Paulo, ANPED, n. 5/6.

(2003). Espaços de juventude. In: Freitas, Maria Virgínia; Papa, Fernanda de Carvalho. Políticas públicas: juventude em pauta. São Paulo: Cortez.

y Branco, Pedro Paulo Martoni (2004). Retratos da Juventude Brasileira: analises de uma pesquisa nacional. São Paulo: Instituto Cidadania, Editora Fundação Perseu Abramo. 
Belo Horizonte (2004). Prefeitura. Secretaria Municipal de Coordenação das Políticas Sociais. Programa para jovens: avaliação - agosto 2004. Belo Horizonte.

(2004 A). Secretaria Municipal de Coordenação das Políticas Sociais. Programa para jovens: resumo. Belo Horizonte.

Bergo, Renata Silva (2005). Reiventando a escola: ideais, práticas e possibilidades de um projeto socioeducativo. Dissertação (Mestrado de Educação) Faculdade de Educação da UFMG, Belo Horizonte.

BRASIL (2001). Ministério da Previdência e Assistência Social. Secretaria de Estado de Assistência Social. Portaria n. 879, de 3 de dezembro de 2001. Estabelece normas e diretrizes do projeto Agente Jovem de Desenvolvimento Social e Humano e do Projeto Centro de Juventude. Brasília.

Brenner, Ana Karina; Dayrell, Juarez; Carrano, Paulo (2004). Culturas do lazer e do tempo livre dos jovens brasileiros. In: Abramo, Helena \& Branco, Pedro Paulo Martoni. Retratos da Juventude Brasileira: análises de uma pesquisa nacional. São Paulo: Instituto Cidadania. Editora Fundação Perseu Abramo.

Corti, Ana Paula \& Souza, Raquel (2004). Diálogos com o mundo juvenil: subsídios para educadores. São Paulo: Ação Educativa.

Dayrrell, Juarez (2005). A música entra em cena: o funk e o rap na socialização da juventude. Belo Horizonte: Editora UFMG.

(2005). Relatório Preliminar da pesquisa Juventude, Escolarização e poder local. Mimeo.

Freire, Paulo (1996). Pedagogia da Autonomia: saberes necessários à prática pedagógica. São Paulo: Paz e Terra.

Freitas, Maria Virgínia; Papa, Fernanda de Carvalho (2003). Políticas públicas: juventude em pauta. São Paulo: Cortez.

Lahire, Bernard; Vincente, GUY; THIN, Daniel. "Sobre a história e a teoria da forma escolar". Belo Horizonte: Educação em Revista, n.33. Junho 2001. p 07-47.

Leão, Geraldo.(2004) "A gestão da pobreza juvenil: uma análise de um programa federal de inclusão de jovens pobres". Trabalho apresentado na XXVII Reunião Anual da Anped. Caxambu.

Machado-Pais, José. "A construção sociológica da juventude: alguns contribuíos". Análise Sociológica, v. 25, 1990, n. 105-106.

Martins, José de Souza (1997). Exclusão social e a nova desigualdade. São Paulo: Paulus. 
Morcellini, Mario (1993). Culturas juvenis. Lisboa: Imprensa Nacional Casa da Moeda.

(1997). Passagio al futuro; formazione e sociallizzazione tra vecchi e nuovi media. Milão: Franco Angeli.

Reis, Juliana Batista (2005). Juventude e politicas publicas: reflexões sobre o "Agente Jovem" em Belo Horizonte. (Monografia) UFMG: FAFICH, Belo Horizonte.

Rodrigues, Hila Bernardete Silva (2004). "Políticas públicas e projetos para a juventude: uma análise comparativa de pressupostos e contextos institucionais de duas iniciativas. 2004". Dissertação (Mestrado Administração Pública). Fundação João Pinheiro, Belo Horizonte.

Rua, Maria das Graças (1998). "As políticas públicas e a juventude nos anos 90". In: Jovens acontecendo na trilha das politicas públicas. Brasília, CNPD.

Souza, Regina Magalhães (2003). Escola e juventude: aprender a aprender. São Paulo: Educ/ Paulus.

Sposito, Marilia (2000). "Algumas hipóteses sobre as relações entre movimentos sociais, juventude e educação". Revista Brasileira de Educação. São Paulo, n.13.

A sociabilidade juvenil e a rua; novos conflitos e ação coletiva na cidade. Tempo Social: Revista de Sociologia da USP. São Paulo, v. 5, 1993, n. 1/ 2, p.161-178.

(2002). Juventude, escolarização e poder local: projeto temático. São Paulo. Mimeo.

(2003). “Trajetórias na constituição de políticas públicas de juventude no Brasil". In: Freitas, Maria Virgínia;Papa, Fernanda de Carvalho. Políticas públicas: juventude em pauta. São Paulo: Cortez.

(2004). "Algumas reflexões e muitas indagações sobre as relações entre juventude e escola no Brasil". In: Abramo, Helena \& Branco, Pedro Paulo Martoni. Retratos da Juventude Brasileira: analises de uma pesquisa nacional. São Paulo: Instituto Cidadania, Editora Fundação Perseu Abramo.

\& Corrochano, Carla (2005). A face oculta dos programas de transferência de renda para jovens no Brasil. Mimeo.

Warren, Ilse S. Movimentos em cena... E as teorias por onde andam? (online) Disponível em: www.educacaoonline.pro.br/movimentos_em_cena.asp. Acesso em $1^{\circ}$ jun. 2004. 